\title{
Effects of Cytomegalovirus Infection on Growth Factor Production in Endothelial Cells and Fibroblasts
}

\author{
JEREMY S. GARRETT, ${ }^{1}$ JOANN C. NARUS, JOHN F. BOHNSACK, DAREN E. CARLING, \\ KELLY G. GRIEVES, W. JAMES WALDMAN, AND ROBERT E. SHADDY \\ Department of Pediatrics, University of Utah School of Medicine, Salt Lake City, Utah 84132 [J.S.G., \\ J.C.N., J.F.B., D.E.C., K.C.G., R.E.S.J, and the Department of Pathology, The Ohio State University, \\ Columbus, Ohio 43210-1238 [W.J.W.]
}

\begin{abstract}
To determine whether cytomegalovirus (CMV) infection alters growth factor production from endothelial cells (EC) or fibroblasts, we infected human umbilical vein $\mathrm{EC}$ with $\mathrm{CMV}$ VHL/E, a strain of CMV with affinity for human EC, and we infected human foreskin fibroblasts with CMV AD169. CMV caused cytopathic effect and positive CMV staining by immunofluorescence within $5 \mathrm{~d}$, effects not seen in cells infected with UV-irradiated CMV or in uninfected (control) cells. The supernatants from the EC were assayed for platelet-derived growth factor (PDGF)-like protein using a radioreceptor inhibition assay, and EC and fibroblasts were assayed for basic fibroblast growth factor (bFGF) by Western blot analysis. There were no significant differences in PDGF production between groups of $\mathrm{EC}$ : CMV-infected EC, $13.5 \pm 2.6$; UV-irradiated infected EC, 12.1 \pm 3.6; control EC, $12.9 \pm 1.7 \mathrm{fmol} / 10^{6} \mathrm{EC}$ (mean $\pm \mathrm{SD}, n=10$, $p=\mathrm{NS}$ ). There were also no significant differences in bFGF production between CMV-infected EC, UV-irradiated infected $\mathrm{EC}$, and control EC as evidenced by similar intensity of migration of bFGF as a single band at approximately $18 \mathrm{kD}(n=5)$.
\end{abstract}

\section{ABSTRACT}

In contrast, CMV infection of fibroblasts induced a shift in production of bFGF to higher molecular weight forms migrating at 24 and $26 \mathrm{kD}$ molecular mass. $\alpha$-Interferon failed to alter bFGF production. We conclude that CMV VHL/E infection of $\mathrm{EC}$ does not directly alter PDGF or bFGF production from EC. However, CMV infection of cultured human fibroblasts qualitatively alters bFGF by inducing a shift to higher molecular weight forms. (Pediatr Res 38: 1003-1008, 1995)
EC, endothelial cell
Abbreviations
CMV, cytomegalovirus
PDGF, platelet-derived growth factor
bFGF, basic fibroblast growth factor
HUVEC, human umbilical vein endothelial cell
CPE, cytopathic effect
HS, heparin Sepharose
TBST, Tris-buffered saline with Tween 20

The major limiting factor to long-term survival after both pediatric and adult human heart transplantation is accelerated graft arteriosclerosis $(1,2)$. Although immunologic injury secondary to rejection or infection has been widely implicated as a contributing factor to its pathogenesis, the mechanisms of this process remain unknown. Pathologically, the arteriosclerosis seen after heart transplantation is quite variable, ranging from diffuse to segmental and from atheromatous to entirely composed of myointimal proliferation (3). Vascular cells im-

Received November 11, 1994; accepted June 29, 1995

Correspondence and reprint requests: Robert E. Shaddy, M.D., Division of Cardiology, Primary Children's Medical Center, 100 North Medical Dr., Salt Lake City, UT 84113.

Funded in part by a grant from the American Heart Association, Utah Affiliate (91-49-07).

Portions of this work were presented at the annual meetings of the Society for Pediatric Research in 1992 and 1994.

${ }^{1}$ Current address: Sunrise Children's Hospital, 3186 So. Maryland Parkway, Las Vegas NV 89109. plicated in this process include EC, smooth muscle cells, and the so-called myofibroblasts that are internal to the internal elastic lamina (4). An association between CMV infection and an increased risk of development of graft coronary vasculopathy has been found (5-7); however, the mechanisms through which CMV may promote graft coronary vasculopathy have yet to be defined. CMV increases HLA class I antigen expression on human EC (8) and HLA class II antigen expression on rat cardiac EC (9), activates $\mathrm{CD}^{+}{ }^{+} \mathrm{T}$ cells to induce class II antigen expression on EC (10), and increases vascular cell adhesion molecule- 1 in transplanted human hearts (11). This would suggest a possible indirect method by which CMV infection causes graft coronary vasculopathy. Little is known, however, about the direct effects of CMV on growth factor expression from cells.

PDGF is a cationic polypeptide with broad mitogenic activity including stimulation of mesenchymal proliferation at sites 
of tissue injury (12). Endothelial cells synthesize and secrete a protein similar to PDGF, which can be stimulated by a variety of agents including thrombin, IL-1, and tumor necrosis factor (13-16). In human nontransplant atheroma, PDGF-like mitogen has been localized to both smooth muscle cells (17) and to macrophages within the atheromatous lesions (18). Indirect evidence for alterations in PDGF during allograft rejection comes from the finding that there is increased expression of PDGF receptors during rejection, both on vascular smooth muscle of kidney transplants (19) and in the arteries and myocardium of rat heart allografts (20).

BFGF is a mitogen for endothelial, smooth muscle, and connective tissue cells (21). bFGF is produced by vascular cells and either remains cell-associated (22) or is deposited into the subcellular matrix (23). bFGF has been found in increased amounts within the lesions of human graft coronary vasculopathy (24), suggesting that synthesis of bFGF by vascular cells may be altered during allograft rejection. However, others have found no evidence of bFGF RNA in transplanted heart biopsies, suggesting that bFGF is not increased after transplantation (25). $\alpha$-Interferon is a cytokine produced in vivo by cells such as fibroblasts in response to viral infection (26). In vitro, $\alpha$-interferon induces formation of endothelial cell tubules, an angiogenic-like property often ascribed to bFGF (27).

We hypothesized that CMV may either directly or indirectly (through $\alpha$-interferon) cause increased production of PDGFlike protein or bFGF from endothelial cells or fibroblasts, thus providing a mechanism of altered growth factor production after CMV infection. The purpose of this study was to investigate the effects of CMV infection on PDGF and bFGF production from fibroblasts and EC.

\section{METHODS}

Cell cultures. HUVEC were cultured by methods similar to those previously described by this laboratory (28). Primary cultures through second passage cultures were used in all studies.

Swiss Albino 3T3 cells (American Type Culture Collection, Rockville, MD) were grown in $75-\mathrm{cm}^{2}$ tissue culture flasks and maintained in complete 3T3 cell medium containing $90 \%$ McCoy's 5A medium (modified with L-glutamine, without sodium bicarbonate) (Sigma Chemical Co., St. Louis, MO) and $10 \%$ FCS. Medium was changed twice weekly, and the cells were passed in subculture 1:3 upon reaching confluence. $\mathrm{Hu}-$ man foreskin fibroblasts (American Type Culture Collection) were routinely passaged using trypsin and M199 with $10 \%$ FCS. Periodically (every 10-12 passages), cultures were regenerated from a stock of fibroblasts stored in liquid nitrogen.

Infection of endothelial cells and fibroblasts. CMV strain VHL/E was prepared as previously described (29). For acute infection studies of EC, HUVEC were grown to $75 \%$ confluence in fibronectin-coated $75-\mathrm{cm}^{2}$ tissue culture flasks. Cultures were inoculated with CMV VHL/E stock diluted with complete EC medium. After adsorption for $1 \mathrm{~h}$, an equal amount of complete EC medium supplemented with EC growth supplement and heparin was added to each flask.
Infection of cells was allowed to continue until maximum CPE was noted, but short of cell death.

Cultured fibroblasts were infected with CMV as previously described (30). Cells were plated and grown to $80 \%$ preconfluence and then coincubated with CMV AD169 for $1 \mathrm{~h}$. The cells were then washed and refed with complete culture medium. After this initial infection, cell cultures were incubated for 4-9 d (5.4 \pm 1.8$)$ and examined daily for CPE. Evidence of CMV infection was verified by periodic examination of cultured cells with immunohistochemical staining with a CMV culture identification test that uses MAb specific for two different human CMV antigens: an immediate-early antigen $\left(M_{\mathrm{r}}=72000\right)$ and early antigen $\left(M_{\mathrm{r}}=50000\right)$. Cell nuclei, which stain for the CMV nuclear antigens, display fluorescent green staining (Syva Co., Palo Alto, CA).

Sham infection was performed by incubating HUVEC or fibroblasts with CMV VHL/E or CMV AD169, respectively, which had been exposed to UV light for $60 \mathrm{~min}$ to inactivate the virus.

PDGF-like protein secretion from $\mathbf{E C}$. EC-conditioned medium was collected from the EC monolayers and assayed for the presence of PDGF-like protein using a ${ }^{125}$ I-PDGF (PDGF, Inc., Boston, MA) competitive radioreceptor binding assay as previously described (31). Medium used for collection and analysis of PDGF-like protein was standard EC growth medium that contained FCS at the onset of experiments and then became gradually depleted of serum by the EC during continued culture and incubation at $37^{\circ} \mathrm{C}$ over the ensuing $5.4 \pm 1.8$ d. Identical media were used in both sets of control cells (UV-irradiated virus/sham-infected EC and untreated EC), which were cultured in parallel with test plates under identical conditions. At the end of the CMV infection period, microscopic examination of the EC monolayers demonstrated viable EC without significant monolayer disruption except in the areas of CPE. Attempts at experiments without the presence of FCS in the initial EC medium resulted in a significant loss of viable cells during CMV infection.

Western blot analysis. After removal of the conditioned medium, the flasks were rinsed twice in $5 \mathrm{~mL}$ of ice-cold PBS with $0.05 \%$ EDTA. Cells and matrix were then taken up with scraping in three successive washings. The first washing was in $2 \mathrm{~mL}$ of ice-cold $2 \mathrm{M} \mathrm{NaCl}, 25 \mathrm{mM}$ sodium acetate, $\mathrm{pH} 4,1$ $\mathrm{mM}$ phenylmethylsulfonyl fluoride, $0.05 \%$ sodium azide, and the second and third washings were in $5 \mathrm{~mL}$ of ice-cold PBS with $0.05 \%$ EDTA and $0.05 \%$ sodium azide. Cell suspensions were sonicated for $1 \mathrm{~min}$ on ice, pulsed at $60 \%$ with a cell disrupter (Model W-225 Heat Systems-Ultrasonics, Inc., Plainview, NY), and then centrifuged at $4^{\circ} \mathrm{C}$ at $13000 \times g$ for 30 min. Cell lysates were transferred to $12-\mathrm{mL}$ centrifuge tubes (Sarstedt, Newton, NC) and either frozen at $-70^{\circ} \mathrm{C}$ or procedures were immediately followed for preparation of a Western blot for the study of bFGF.

To recover bFGF from crude cell lysates, $40 \mu \mathrm{L}$ of $\mathrm{HS}$ beads were added to each sample, incubated overnight on an endover-end rotator at $4^{\circ} \mathrm{C}$, and separated by brief centrifugation at $1000 \times g$. Using radioactively labeled recombinant bFGF, approximately $85 \%$ of bFGF was found to be retained on the HS beads under these conditions. The HS beads were then 
transferred to 1.5-mL Eppendorf tubes, washed twice on ice with $1 \mathrm{~mL}$ of PBS/EDTA, and boiled for $10 \mathrm{~min}$ after the addition of $28 \mu \mathrm{L}$ of concentrated sample buffer consisting of $120 \mathrm{mM}$ Tris, $\mathrm{pH} 6.8,4 \% \mathrm{SDS}$, and $19 \%$ glycerol with $2 \%$ $\beta$-mercaptoethanol. Samples (HS beads and liquid) were loaded directly onto prepoured polyacrylamide gradient (420\%) gels (Novex, Encitas, CA) and electrophoresed using low molecular weight markers (Amersham Corp., Arlington Heights, IL) as standards. Proteins were then transferred to nitrocellulose for $2 \mathrm{~h}$ at $90 \mathrm{~V}$ constant voltage, washed with 20 $\mathrm{mL}$ of PBS, and fixed with $25 \mathrm{~mL}$ of PBS, $0.5 \%$ ( $\mathrm{vol} / \mathrm{vol}$ ) glutaraldehyde for $15 \mathrm{~min}$. Fixation was stopped by incubation with $25 \mathrm{~mL}$ of $50 \mathrm{mM}$ glycine/PBS for $10 \mathrm{~min}$. The nitrocellulose was next washed with $25 \mathrm{~mL}$ of Tris-buffered saline with TBST, blocked by overnight incubation in 5\% Carnation instant nonfat dried milk, incubated with $15 \mathrm{~mL}$ of $100 \mathrm{ng} / \mathrm{mL}$ DE6 anti-bFGF IgG1 murine MAb (a generous gift from the DuPont Corporation, Wilmington, DE) (32) for $2 \mathrm{~h}$, and incubated with $25 \mathrm{~mL}$ of $600 \mathrm{ng} / \mathrm{mL}$ biotinylated rabbit anti-mouse FAB2 antibody fragments for $40 \mathrm{~min}$. The nitrocellulose was again washed three times with $25 \mathrm{~mL}$ of TBST, incubated for 25 min with $25 \mathrm{~mL}$ of Extravidin (Sigma Chemical Co.) diluted 1:5000 in TBST, washed an additional three times in TBST, and then washed once again with alkaline phosphatase buffer (containing $5 \mathrm{mM} \mathrm{MgCl} 2$ ). Finally, the blot was developed with alkaline phosphatase substrate (nitro blue tetrazolium/5-bromo-4-chloro-3-indoyl phosphate). All incubations were performed at room temperature. Equal protein loading of lanes was verified initially with Lowry determinations and then by Coomassie Brilliant Blue staining of residual proteins in each experiment.

Data analysis. Comparisons between groups were made using a paired $t$ test. All data are expressed as mean \pm SD.

\section{RESULTS}

EC monolayers could be reproducibly infected with CMV $\mathrm{VHL} / \mathrm{E}$ as evidenced by the presence of CPE, whereas those incubated with UV-irradiated CMV VHL/E (sham CMV) and control EC demonstrated normal morphology without evidence of CPE (Fig. 1). Similarly, EC monolayers infected with CMV
VHL/E also demonstrated immunofluorescent staining of CMV, whereas those incubated with UV-irradiated CMV VHL/E (sham CMV) or control EC showed negative immunofluorescent staining (Fig. 2). CMV AD169 caused similar effects in fibroblasts.

CMV infection of EC monolayers did not alter PDGF-like protein secretion. In 10 experiments, PDGF-like protein secretion was similar between groups of EC monolayers: CMVinfected $\mathrm{EC} 13.5 \pm 2.6 \mathrm{fmol} / 10^{6} \mathrm{EC}$; UV-irradiated infected $\mathrm{EC} 12.9 \pm 1.7 \mathrm{fmol} / 10^{6} \mathrm{EC}$; control EC $12.1 \pm 3.6 \mathrm{fmol} / 10^{6}$ $\mathrm{EC}(p=\mathrm{NS})$ (Fig. 3).

Western blot analysis of bFGF production from EC monolayers showed no differences in staining intensity of bFGF migrating as a single band at approximately $18 \mathrm{kD}$ from cell lysates of CMV-infected EC, sham CMV-infected EC, and control ECs (Fig. 4). In contrast, Western blot analysis of cell lysates of fibroblasts showed that bFGF present in control uninfected fibroblasts (Fig. 5, lane 1) migrates as a single molecular weight band, similar to that of the recombinant bFGF standards (Fig. 5, lanes 3, 4, and 5). However, CMVinfected cell lysates demonstrated a shift to higher molecular weight forms of bFGF, migrating at 24- and $26-\mathrm{kD}$ molecular mass (Fig. 5, lane 2). Additionally, diminished amounts of the smaller molecular mass $18-\mathrm{kD}$ form found in control fibroblasts were present with CMV infection. Sham-infected fibroblasts showed no alteration in bFGF detection by Western blot.

Treatment of fibroblasts with $\alpha$ interferon failed to induce a shift to higher molecular weight forms of bFGF. Incubations as long as $72 \mathrm{~h}$ failed to alter bFGF production from fibroblasts. Other mitogens, such as IL-1, 12-O-tetradecanoylphorbol 13acetate and thrombin, had a similar effect to that of $\alpha$-interferon (Fig. 6). Finally, bFGF was not detected in conditioned medium from fibroblasts using Western blot analysis.

\section{DISCUSSION}

CMV infection of heart transplant patients is associated with arteriolar EC accumulation and with increased intimal thickness of intramyocardial vessels (33). Because EC have been implicated in the development of graft coronary vasculopathy (34-36), the question arises as to whether or not there exists a
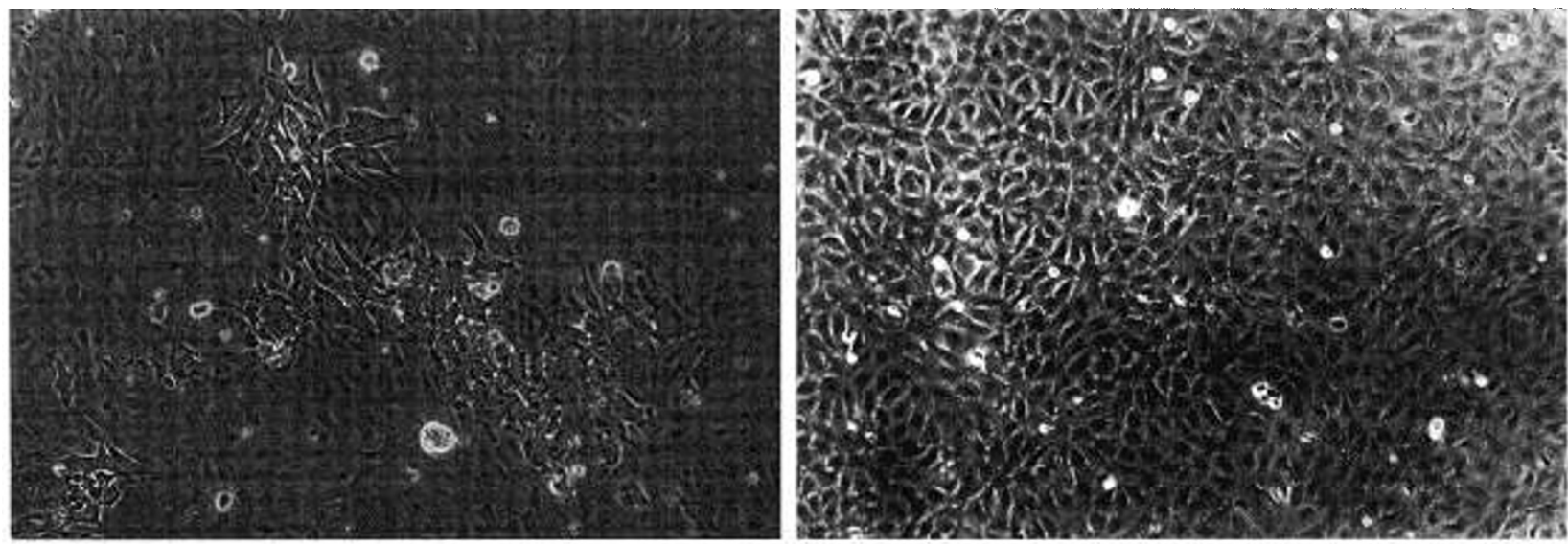

Figure 1. EC monolayer (left) infected with CMV VHL/E demonstrating cytopathic effect and (right) incubated with UV-irradiated CMV VHL/E (sham CMV) demonstrating normal morphology without evidence of cytopathic effect. 

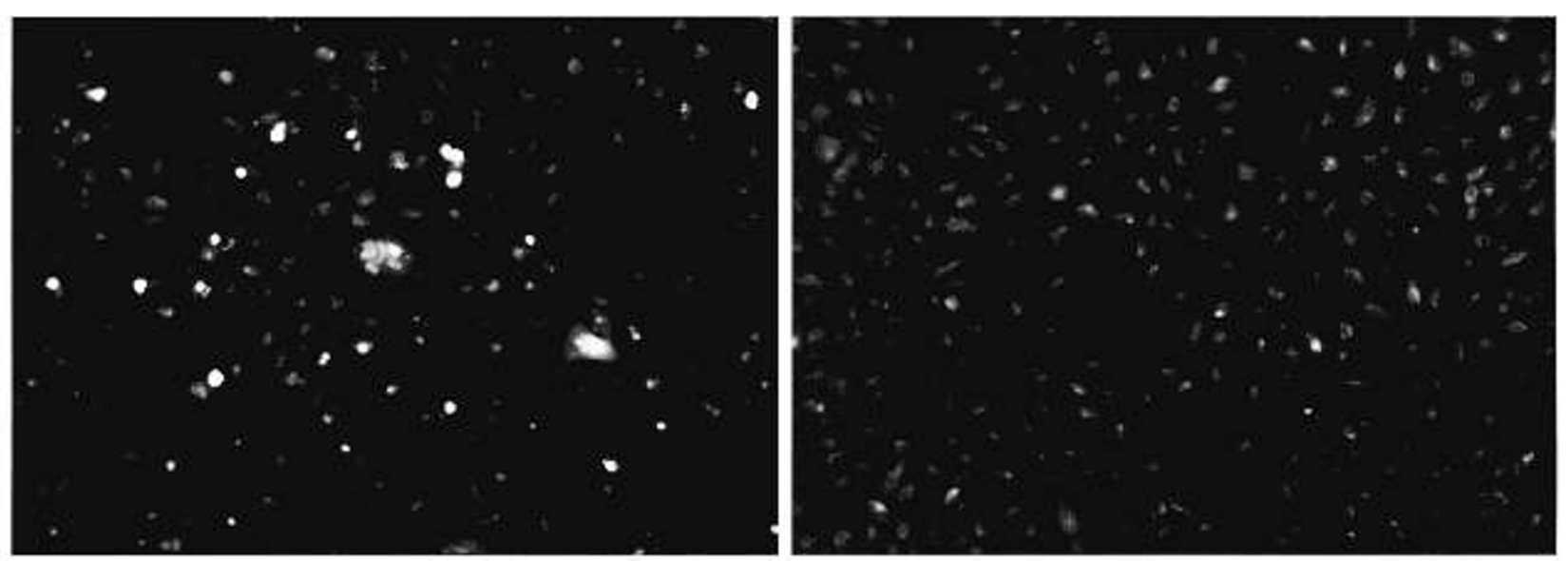

Figure 2. EC monolayer (left) infected with CMV VHL/E demonstrating immunofluorescent staining of CMV and (right) incubated with UV-irradiated CMV (sham CMV) showing negative immunofluorescent staining. The immunofluorescent staining assay employs MAb specific for two different human CMV antigens: an immediate-early antigen $\left(M_{\mathrm{r}}=72000\right)$ and early antigen $\left(M_{\mathrm{r}}=50000\right)$. Cell nuclei display fluorescent green staining.

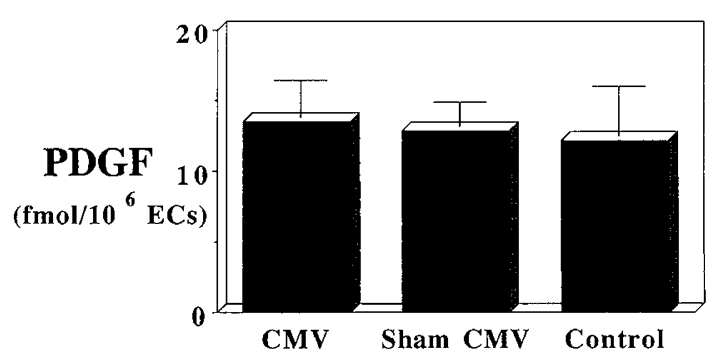

Figure 3. PDGF-like protein secretion from CMV-infected EC, sham (UVirradiated) CMV-infected EC, and control EC $(n=10)$. No significant differences were noted between groups.

causative relationship between CMV infection, EC activation, and graft coronary vasculopathy. In this study, we attempted to determine whether in vitro CMV infection of EC monolayers alters the production or release of PDGF-like proteins or bFGF. Although CMV adequately infected HUVEC, there was no alteration in production of PDGF-like proteins from the EC monolayers. Residual PDGF-like protein initially present in the FCS at the time of the initiation of CMV infection could have still been present in the medium at the time of removal of the conditioned medium. This could have accounted for the somewhat elevated absolute levels of control PDGF-like protein production (12-13 fmol/10 6 EC) compared with previously reported baseline values of $5-6 \mathrm{fmol} / 10^{6} \mathrm{EC}$ in previous experiments from this laboratory, in which plasma-derived serum was used instead of FCS (31). However, it is also possible that the prolonged incubation time of the $\mathrm{EC}$ in this experiment $(5.4 \pm 1.8 \mathrm{~d})$ may also account for the increased expression of PDGF-like protein. In any event, the presence of residual PDGF-like protein in the conditioned medium in these experiments cannot account for the lack of differences in PDGF-like protein secretion between CMV-infected EC and both sets of controls, because they were incubated under identical conditions.

Similar to PDGF-like protein, there were no differences in bFGF production from $\mathrm{EC}$ after infection with CMV. This suggests that the effects of CMV on EC does not include alterations in growth factor and thus that CMV infection of transplanted hearts does not increase the incidence of graft
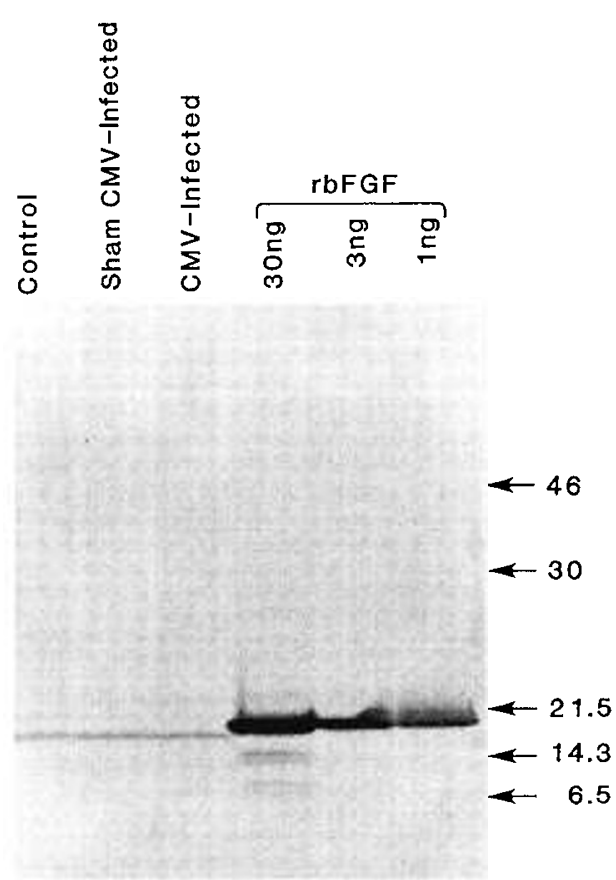

Figure 4. Western Blot analysis of bFGF production from EC monolayers showing no differences in staining intensity of bFGF migrating as a single band at $18 \mathrm{kD}$ from cell lysates from control EC (lane 1), sham (UV-irradiated) CMV-infected EC (lane 2), and CMV-infected EC (lane 3). Lanes 3, 4, and 5: Recombinant bFGF $(r b F G F)$ added to the gel directly, demonstrating a single band representing 30,3 , and $1 \mathrm{ng}$ recombinant $\mathrm{bFGF}$. Numbers to the right of the gel represent molecular weight $\times 10^{3}$.

coronary vasculopathy through a direct effect on PDGF or bFGF production from EC. However, because CMV alters HLA class I and vascular cell adhesion molecule- 1 expression on EC and activates T cells to induce MHC class II expression on EC, this suggests that the effects of CMV on EC and graft coronary vasculopathy are indirect effects. Our data support this. Although it is certainly possible that other growth factors may be directly stimulated by CMV infection of cell cultures, PDGF and bFGF appear to be unaffected.

In contrast, CMV infection of cultured human fibroblasts does appear, under certain conditions, to qualitatively alter cellularly associated bFGF by inducing a shift to higher mo- 


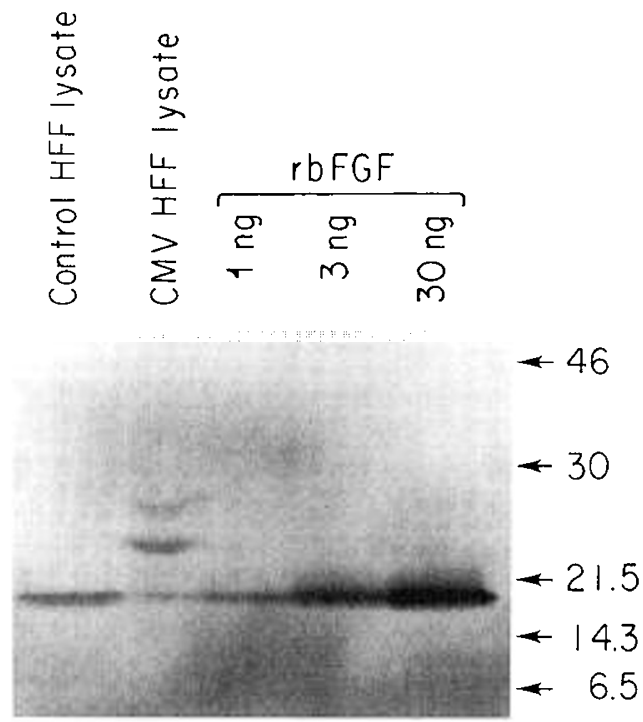

Figure 5. Western Blot analysis of bFGF demonstrating presence of higher molecular weight forms of bFGF during CMV infection. Lane 1: Uninfected (control) human foreskin fibroblast $(H F F)$ cell lysate showing single band of bFGF. Lane 2: HFF cell lysate after 7 d of infection with CMV AD169, demonstrating three separate bands of bFGF, two of which are higher molecular weight forms. Lanes 3, 4, and 5: Recombinant bFGF added to the gel directly, demonstrating a single band representing 1,3 , and 30 ng of recombinant bFGF. Numbers to the right of the gel represent molecular weight $\times$ $10^{3}$.

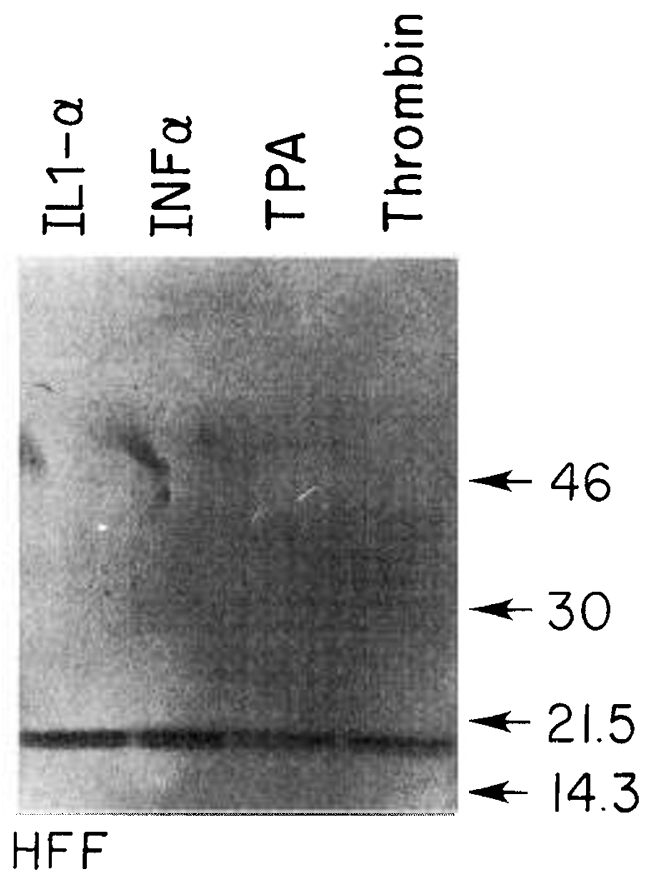

Figure 6. Western blot analysis of bFGF demonstrating no alteration in bFGF production from human foreskin fibroblast $(H F F)$ after treatment for $24 \mathrm{~h}$ with IL-1 $\alpha, 2 \mathrm{ng} / \mathrm{mL} ; \alpha$-interferon $(I N F \alpha), 1000 \mathrm{U} / \mathrm{mL} ; 12-O$-tetradecanoylphorbol 13-acetate $(T P A), 200 \mathrm{ng} / \mathrm{mL}$; or thrombin, $10 \mathrm{U} / \mathrm{mL}$. Numbers to the right of the gel represent molecular weight $\times 10^{3}$.

lecular weight forms. From the work of others (37-39), these higher molecular weight forms have been shown to represent $\mathrm{N}$-terminal extensions of the protein that predominantly have a nuclear distribution. From this same work, it has been shown that, without this $\mathrm{N}$-terminal extension, bFGF remains predom- inantly cytoplasmically associated. Thus, because CMV can induce a shift to these higher molecular weight forms in human fibroblasts, it likely alters the subcellular distribution of bFGF. Both classic $18-\mathrm{kD}$ bFGF and high molecular mass bFGF have similar receptor-binding activity and biologic effects on cell proliferation, chemotaxis, and angiogenesis when exogenously added to EC cultures (40). However, exogenous production of only high molecular weight bFGF in transfected cell lines has been observed to produce phenotypic differences (38). Furthermore, data from expression in NIH 3 T3 fibroblasts demonstrating differences in both morphology and tumorigenicity has suggested a functional role for high molecular weight bFGF (41). Interestingly, in vivo expression of high molecular weight bFGF within the rat heart appears to be under both developmental and hormonal control (42), and ventricular expression of bFGF mRNA is significantly altered after cardiac transplantation (43).

It is possible that by inducing a shift to higher molecular weight forms of bFGF, CMV may alter the deposition of bFGF into the subcellular matrix and thus contribute to increased myointimal proliferation. This study also shows that $\alpha$-interferon (a product of virus-infected cells) does not alter production of bFGF. The fact that fibroblasts produced, but did not actively secrete, bFGF in this study supports previous studies which state that bFGF lacks a signal peptide and thus is not normally secreted by cells. Even when higher molecular weight forms of bFGF were produced by fibroblasts, these forms were not found in the conditioned medium. In this study, the extracellular matrix was not separated from the cell layer, and thus it is not possible to know whether the bFGF was isolated to the cells, the subcellular matrix, or both.

We conclude that, although CMV VHL/E effectively infects human $\mathrm{EC}$, this CMV infection does not directly alter PDGF or bFGF production from EC. However, CMV infection of fibroblasts induces a shift to production of higher molecular weight forms of bFGF. The significance of the production of higher molecular weight forms of bFGF is unknown, but we speculate that this may alter the local autocrine or paracrine function of bFGF.

Acknowledgment. The authors thank Kris Sjoblom for her expert editorial assistance and preparation of this manuscript.

\section{REFERENCES}

1. O'Neill BJ, Pflugfelder PW, Singh NR, Menkis AH, McKenzie FN, Kostuk WJ 1989 Frequency of angiographic detection and quantitative assessment of coronary arterial disease one and three years after cardiac transplantation. Am J Cardiol 63:1221-1226

2. Braunlin EA, Hunter DW, Canter CE, Gutierrez FR, Ring WS, Olivari MT, Titus JL, Spray TL, Bolman RM 1991 Coronary artery disease in pediatric cardiac transplant recipients receiving triple-drug immunosuppression. Circulation 84(suppl III):303309

3. Johnson DE, Gao SZ, Schroeder JS, DeCampli WM, Billingham ME 1989 The spectrum of coronary artery pathologic findings in human cardiac allografts. J Heart Transplant 8:349-359

4. Williams SK 1991 Regulation of intimal hyperplasia: do endothelial cells participate? Lab Invest 64:721-724

5. Grattan MT, Moreno-Cabral C, Starnes V, Oyer P, Stinson E, Shumway N 1989 Cytomegalovirus infection is associated with cardiac allograft rejection and atherosclerosis. JAMA 261:3561-3566

6. McDonald K, Rector T, Braunlin E, Kubo S, Olivari M 1989 Association of coronary artery disease in cardiac transplant recipients with cytomegalovirus infection. Am J Cardiol 64:359-362 
7. Loebe M, Schuler S, Zais O, Wanecke H, Fleck E, Hetzer R 1990 Role of cytomegalovirus infection in the development of coronary artery disease in the transplanted heart. J Heart Transplant 9:707-711

8. Tuder RM, Weinberg A, Panajotopoulos N, Kalil J 1994 Cytomegalovirus infection amplifies class I major histocompatibility complex expression on cultured human endothelial cells. J Heart Lung Transplant 13:129-138

9. Ustinov JA, Loginov RJ, Bruggeman CA, van der Meide PH, Hayry PJ, Lautenschlager IT 1993 Cytomegalovirus induced class II expression in rat heart endothelial cells. J Heart Lung Transplant 12:644-651

10. Waldman WJ, Knight DA, Adams PW, Orosz CG, Sedmak DD 1993 In vitro induction of endothelial HLA class II antigen expression by cytomegalovirusactivated $\mathrm{CD}^{+}$cells. Transplantation 56:1504-1512

11. Koskinen PK 1993 The association of the induction of vascular cell adhesion molecule- 1 with cytomegalovirus antigenemia in human heart allografts. Transplantation 56:1103-1108

12. Ross RR, Raines EW, Bowen-Pope DF 1986 The biology of platelet-derived growth factor. Cell 46:155-169

13. Harlan JM, Thompson RL, Ross RR, Bowen-Pope DF 1986 Alpha-thrombin induces release of platelet-derived growth factor-like molecules by cultured endothelial cells. J Cell Biol 103:1129-1133

14. Raines EW, Dower SK, Ross R 1989 Interleukin-1 activity for fibroblasts and smooth muscle cells is due to PDGF-AA. Science 243:393-396

15. Hajjar KA, Hajjar DP, Silverstein RL, Nachman RL 1987 Tumor necrosis-mediated release of platelet-derived growth factor from cultured endothelial cells. J Exp Med 66:235-245

16. Bradham DM, Igarashi A, Potter RL, Grotendorst GR 1991 Connective tissue growth factor: a cysteine-rich mitogen secreted by human vascular endothelial cells is related to the SRC-induced immediate early gene product CEF-10. J Cell Biol 114:12851294

17. Libby P, Warner SJC, Salomon RN, Birinyi LK 1988 Production of platelet-derived growth factor-like mitogen by smooth-muscle cells from human atheroma. $\mathrm{N}$ Engl J Med 318:1493-1498

18. Ross R, Masuda J, Raines E, Gown AM, Katsuda S, Sasahara M, Malden LT, Masuko H, Sato H 1990 Localization of PDGF-B protein in macrophages in all phases of atherogenesis. Science 248:1009-1012

19. Rubin K, Hansson GK, Ronnstrand L, Claesson-Welch L, Fellstrom B, Tingstrom A, Larsson E, Klareskog L, Heldin C, Terracio L 1988 Induction of B-type receptors for platelet-derived growth factor in vascular inflammation: possible implications for development of vascular proliferative lesions. Lancet 1:1353-1359

20. Higgy NA, Davidoff AW, Grothman GT, Hollenberg MD, Benediktsson H, Paul LC 1991 Expression of platelet-derived growth factor receptor in rat heart allografts. J Heart Lung Transplant 10:1012-1022

21. Gospodarowicz D, Neufeld G, Schweigerer L 1987 Fibroblast growth factor: structural and biological properties. J Cell Physiol Suppl 5:15-26

22. Vlodavsky I, Fridman R, Sullivan R, Sasse J, Klagsbrun M 1987 Aortic endothelia cells synthesize basic fibroblast growth factor which remains cell associated and platelet-derived growth factor-like protein which is secreted. J Cell Physiol 131:402406

23. Vlodavsky I, Folkman J, Sullivan R, Fridman R, Ishai-Michaeli R, Sasse J, Klagsbrun M 1987 Endothelial cell-derived basic fibroblast growth factor: synthesis and deposition into the subendothelial extracellular matrix. Proc Natl Acad Sci USA 84:22922296

24. Isik FF, Valentine HA, McDonald TO, Baird A, Gordon D 1991 Localization of bFGF in human transplant coronary atherosclerosis. Ann NY Acad Sci 638:487-488

25. Zhao X-M, Yeoh T-K, Frist WH, Porterfield DL, Miller GG 1994 Induction of acidic fibroblast growth factor and full-length platelet-derived growth factor expression in human cardiac allografts. Circulation 90:677-685
26. Durum SK, Oppenheim JJ 1989 Macrophage-derived mediators: interleukin 1, tumor necrosis factor, interleukin 6, interferon, and related cytokines. In: Paul WE (ed) Fundamental Immunology. Raven Press, New York, pp 647-651

27. Maheshwari RK, Srikantan V, Bhartiya D, Kleinman HK, Grant DS 1991 Differential effects of interferon $\gamma$ and $\alpha$ on in vitro model of angiogenesis. $J$ Cell Physiol 146:164-169

28. Shaddy RE, Mak C, Zimmerman GA 1990 The serum of moderately-severely rejecting heart transplant patients induces peripheral blood mononuclear cells to injure endothelial cells. Transplantation 49:1013-1015

29. Waldman WJ, Sneddon JM, Stephens RE, Roberts WH 1989 Enhanced endothelial cytopathogenicity induced by a cytomegalovirus strain propagated in endothelial cells. J Med Virol 28:223-230

30. Van Dam-Mieras M, Bruggeman C, Muller A, Debie W, Zwaal R 1987 Induction of endothelial cell procoagulant activity by cytomegalovirus infection. Thrombos Res 47:69-75

31. Shaddy RE, Hansen JC, Cowley CG 1992 Effects of T cells on platelet-derived growth factor-like protein from endothelial cells. J Heart Lung Transplant 11:48-57

32. Reilly TM, Taylor DS, Herblin WF, Thoolen MJ, Chiu AT, Watson DW, Timmermans PB 1989 Monoclonal antibodies directed against basic fibroblast growth factor which inhibit its biological activity in vitro and in vivo. Biochem Biophys Res Commun 164:736-743

33. Koskinen PK, Nieminen MS, Krogerus LA, Lemstrom KB, Mattila SP, Hayry PK, Lautenschlager IT 1993 Cytomegalovirus infection and accelerated cardiac allograft vasculopathy in human cardiac allografts. J Heart Lung Transplant 12:724-729

34. Salomon RN, Hughes CCW, Schoen FJ, Payne DD, Pober JS, Libby P 1991 Human coronary transplantation-associated arteriosclerosis. Evidence for a chronic immune reaction to activated graft endothelial cells. Am J Pathol 138:791-798

35. Paavonen T, Mennander A, Lautenschlager I, Mattila S, Hayry P 1993 Endothelialitis and accelerated arteriosclerosis in human heart transplantation. J Heart Lung Transplant 12:117-122

36. Crisp SJ, Dunn MJ, Rose ML, Barbir M, Yacoub MH 1994 Antiendothelial antibodies after heart transplantation: the accelerating factor in transplant-associated coronary artery disease? J Heart Lung Transplant 13:81-92

37. Brigstock DR, Klagsbrun M 1991 Subcellular distribution of multiple molecular weight forms of bFGF in hepatoma cells. Ann NY Acad Sci 638:427-430

38. Rifkin DB, Quarto N, Mignatti P, Bizik J, Moscatelli D 1991 New observations on the intracellular localization and release of bFGF. Ann NY Acad Sci 638:204-206

39. Quarto N, Finger FP, Rifkin DB 1991 The NH2-terminal extension of highmolecular-weight basic fibroblast growth factor is a nuclear targeting signal. J Cell Physiol 147:311-318

40. Gualandris A, Urbinate C, Rusnati M, Ziche M, Presta M 1994 Interaction of high-molecular-weight basic fibroblast growth factor with endothelium: biologic activity and intracellular fate of human recombinant $M_{\mathrm{r}} 24,000 \mathrm{bFGF}$. J Cell Physiol 161:149-59

41. Quarto N, Talarico D, Florkiewicz R, Rifkin DB 1991 Selective expression of high molecular weight basic fibroblast growth factor confers a unique phenotype to NIH 3T3 cells. Cell Regul 2:699-708

42. Liu L, Doble BW, Kardami E 1993 Perinatal phenotype and hypothyroidism are associated with elevated levels of 21.5 to $22-\mathrm{kDa}$ basic fibroblast growth factor in cardiac ventricles. Dev Biol 157:507-516

43. Ationu A, Carter N 1994 Ventricular expression of basic fibroblast growth factor gene after orthotopic cardiac transplantation. Transplantation 57:1364--1366 